\title{
Relações treonina:lisina digestíveis para suínos na fase inicial, alimentados com rações de baixa proteína, calculadas de acordo com o conceito de energia líquida
}

[Digestible threonine:lysine ratios for starting pigs fed low protein diets, considering net energy concept]

\author{
D. Paiano $^{1}$, I. Moreira ${ }^{2}$, N. Silvestrin ${ }^{3}$, P.L.O. Carvalho ${ }^{4}$, M.A.A. Silva ${ }^{5}$, L.S. Perdigão $o^{2,6}$ \\ ${ }^{1}$ Departamento de Zootecnia - CEO-UDESC \\ Rua Benjamin Constant 164D \\ 89802-002 - Chapecó, SC \\ ${ }^{2}$ Departamento de Zootecnia - UEM - Maringá, PR \\ ${ }^{3}$ Aluno de graduação - UEM - Maringá, PR \\ ${ }^{4}$ Aluno de pós-graduação - UEM - Maringá, PR \\ ${ }^{5}$ Zootecnista autônomo \\ ${ }^{6}$ Bolsista $\mathrm{AT} / \mathrm{CNPq}$
}

\begin{abstract}
RESUMO
Foram realizados dois experimentos com o objetivo de estudar, no primeiro, o efeito de diferentes relações treonina:lisina digestíveis (TL) sobre a utilização do nitrogênio $(\mathrm{N})$ em suínos na fase inicial, dos 15 aos $30 \mathrm{~kg}$ de peso, e, no segundo, o efeito dessas relações sobre o desempenho dos animais. No primeiro experimento, foi avaliado o balanço de nitrogênio, utilizando-se 20 suínos machos castrados, híbridos comerciais de média a alta

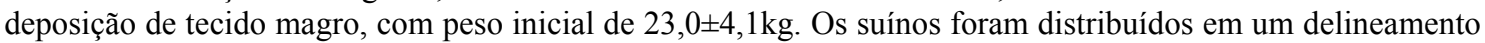
experimental inteiramente ao acaso. As rações continham baixo nível de proteína $(17,3 \%)$, e as relações TL foram: 0,$574 ; 0,624 ; 0,673 ; 0,722$ e 0,772 . A proteína bruta total excretada (PBTE), a proteína bruta retida (PBR) e a utilização líquida da proteína (ULP) apresentaram efeito quadrático, e os melhores valores nas relações foram 0,$648 ; 0,648$ e 0,649 , respectivamente. A melhor relação TL foi 0,649 (média da PBR e ULP). No segundo experimento, foi avaliado o efeito dessa relação sobre o desempenho dos suínos na fase inicial.

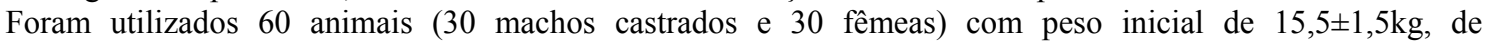
características semelhantes ao primeiro experimento, distribuídos em um delineamento experimental inteiramente ao acaso, em esquema fatorial 5x2 (cinco relações TL e dois sexos, com dois animais por baia). Foram utilizadas seis baias por tratamento, com três de machos e três de fêmeas cada. Não houve efeito da relação TL sobre o consumo diário de ração e o ganho diário de peso, e houve efeito quadrático, com ponto de mínimo, sobre a conversão alimentar com a relação TL de 0,691 . Os resultados indicam que a relação TL de 0,649 maximiza a retenção de nitrogênio e a relação TL de 0,691 permite melhor conversão alimentar para leitões dos 15 aos $30 \mathrm{~kg}$ de peso.
\end{abstract}

Palavras-chave: leitão, aminoácidos, balanço de nitrogênio, proteína ideal, desempenho

\begin{abstract}
Two experiments were carried out to evaluate the effect of digestible threonine:lysine ratio (TL) on nitrogen $(N)$ use and on growth performance of starting pigs (15-30kg). Experiment I evaluated nitrogen balance using twenty high-lean commercial crossbred barrows, with initial weight of $23.0 \pm 4.1 \mathrm{~kg}$. Pigs were allotted in a randomized design. Diets were formulated with low crude protein levels (17.3\%) and TL ratios were: 0.574 ; 0.624; 0.673; 0.722; and 0.772. Excreted crude protein (CPEX), crude protein retention (CPR), and net protein utilization (NPU) showed quadratic effect and the best TL ratio values were achieved at 0.648, 0.648, and 0.649, respectively. The best TL ratio was 0.649 (CPR and NPU means). Experiment II was carried out to examine the same TL ratio effects on the performance of pigs. Sixty pigs (30 barrows and 30 gilts), averaging $15.5 \pm 1.5 \mathrm{~kg}$, used in experiment II, were allotted in a randomized design, following a factorial scheme (5x2), being five TL ratios (same as in experiment I) and two genders. Six pens per treatment (three barrows and
\end{abstract}

Recebido em 26 de maio de 2008

Aceito em 1 de dezembro de 2008

E-mail: diovani@hotmail.com 
three gilts) were used. There was no effect of TL ratio on daily feed intake and on average weight gain. However, the feed:gain ratio showed a quadratic effect and the best TL ratio was achieved at 0.691. The results pointed out that the 0.649 TL ratio maximized nitrogen retention and the 0.694 TL ratio allowed a better feed conversion for starting pigs averaging 15 to $30 \mathrm{~kg}$ of b.w.

Keywords: starting pig, aminoacid, nitrogen balance, ideal protein, performance

\section{INTRODUÇÃO}

O potencial de deposição de proteínas dos suínos é influenciado por fatores como sexo, idade do animal, genótipo (Thong e Liebert, 2004) e teor de proteína da dieta (Rodrigues et al., 2001). Isto indica que animais melhorados para deposição de carne magra têm diferentes exigências, quando comparados a animais de baixo potencial de deposição de carne magra (Moreira, 1998). Consequentemente, fazem-se necessários estudos que avaliem os animais de linhagens modernas nas diferentes situações de criação, estágio de crescimento e idade.

Associada ao crescimento dos animais, existe a preocupação da sociedade e da indústria de produção de suínos com a redução nos custos dos ingredientes, dos produtos finais e, principalmente, com a redução dos poluentes, sendo o nitrogênio um dos principais encontrados nos dejetos de suínos. Uma das formas de se reduzir o teor de nitrogênio excretado é utilizar dietas com baixos níveis proteicos. Segundo Canh et al. (1998), a cada ponto percentual reduzido no teor de proteína bruta (PB), associado com adequada suplementação de aminoácidos, pode-se reduzir em até $10 \%$ a excreção de nitrogênio.

Uma das formas de reduzir o teor de proteína das dietas sem o comprometimento do desempenho dos animais é por meio da utilização do conceito de proteína ideal, ou seja, um perfil ideal de aminoácidos, de modo a suprir adequadamente as exigências de aminoácidos sem deficiência ou excesso. Para isto, têm-se utilizado aminoácidos industriais para suprir os limitantes nas dietas.

Dentre os aminoácidos, a lisina e a treonina são o primeiro e o terceiro limitantes para suínos, em dietas compostas principalmente por milho e farelo de soja (Nutrient..., 1998). Contudo, em muitas dietas, após a suplementação com lisina, a treonina passa a ser o aminoácido limitante. As exigências de treonina, bem como a relação treonina:lisina, indicadas na literatura
(Nutrient..., 1998; Defa et al., 1999; Rodrigues et al., 2001; Arouca et al., 2004, 2005; Rostagno et al., 2005), apresentam grandes variações nas recomendações relacionadas à variação genética, à condição experimental, entre outros fatores.

Assim, o presente experimento foi realizado com o objetivo de estudar a melhor relação treonina:lisina digestíveis (TL) para leitões, dos 15 aos $30 \mathrm{~kg}$ de peso, alimentados com rações de baixo teor de proteína e seus efeitos sobre o balanço de nitrogênio e sobre o desempenho.

\section{MATERIAL E MÉTODOS}

Foram realizados dois experimentos para avaliar a melhor relação TL em relação à retenção de nitrogênio e ao desempenho de leitões. O experimento I consistiu de um ensaio para a determinação do balanço de nitrogênio, utilizandose 20 suínos machos castrados, híbridos comerciais de médio a alto potencial de deposição de carne magra, com peso inicial de $23,0 \pm 4,1 \mathrm{~kg}$. As temperaturas, mínima e máxima médias, registradas durante o primeiro experimento foram de $23,1 \pm 3,5$ e $30,4 \pm 2,8^{\circ} \mathrm{C}$, respectivamente.

Foram formuladas cinco rações com base no conceito de proteína ideal, de acordo com as relações de aminoácidos digestíveis para suínos de médio a alto potencial para deposição de carne magra (325 g/dia), na fase inicial $(22,5 \mathrm{~kg})$, indicadas pelo NRC (Nutrient..., 1998). O teor de PB das rações foi reduzido em 3\%, resultando em dietas com baixa PB (17,3\%), calculadas de modo a serem isoenergéticas e isonutritivas (Tab. 1), exceto para treonina.

As relações treonina:lisina digestíveis (TL) utilizadas nas rações experimentais foram: 0,574; 0,$624 ; 0,673 ; 0,722$ e 0,772 . A composição de aminoácidos do milho e do farelo de soja foi analisada em cromatografia líquida de alta performance (HPLC). Foram utilizados os coeficientes de digestibilidade verdadeira, propostos por Rostagno et al. (2005), para estimar os valores de aminoácidos digestíveis 
dos demais ingredientes utilizados nas rações. Os valores de energia (digestível, metabolizável e líquida) foram calculados com base nos valores propostos por Rostagno et al. (2005). Os valores de cálcio e fósforo foram analisados segundo as metodologias descritas por Silva e Queiroz (2002).
Os animais, distribuídos em delineamento inteiramente ao acaso, com cinco tratamentos (cinco relações TL), foram alojados em gaiolas de metabolismo, semelhantes às descritas por Pekas (1968), e submetidos a um período de sete dias de adaptação às rações, gaiolas, ambiente $\mathrm{e}$ manejo alimentar, seguido por cinco dias de coleta total de excreta.

Tabela 1. Composições centesimal, química e energética das rações experimentais contendo diferentes relações treonina:lisina digestíveis (TL) para suínos na fase inicial (15-30kg)

\begin{tabular}{|c|c|c|c|c|c|}
\hline \multirow{2}{*}{ Ingrediente, $\%$} & \multicolumn{5}{|c|}{ Relação treonina:lisina digestíveis } \\
\hline & 0,574 & 0,624 & 0,673 & 0,722 & 0,772 \\
\hline Milho & 74,12 & 74,12 & 74,12 & 74,12 & 74,12 \\
\hline Farelo de soja & 21,66 & 21,66 & 21,66 & 21,66 & 21,66 \\
\hline Amido & 0,000 & 0,019 & 0,037 & 0,056 & 0,073 \\
\hline Casca de arroz & 0,520 & 0,520 & 0,520 & 0,520 & 0,520 \\
\hline Óleo de soja & 0,250 & 0,250 & 0,250 & 0,250 & 0,250 \\
\hline Fosfato bicálcico & 1,002 & 1,002 & 1,002 & 1,002 & 1,002 \\
\hline Calcário calcítico & 0,866 & 0,866 & 0,866 & 0,866 & 0,866 \\
\hline Sal comum & 0,400 & 0,400 & 0,400 & 0,400 & 0,400 \\
\hline Supl. vit. $+\min ^{1}$ & 0,500 & 0,500 & 0,500 & 0,500 & 0,500 \\
\hline Promotor de crescimento ${ }^{1}$ & 0,050 & 0,050 & 0,050 & 0,050 & 0,050 \\
\hline L-lisina $\mathrm{HCl}-98,5 \%$ & 0,242 & 0,242 & 0,242 & 0,242 & 0,242 \\
\hline DL-metionina - 99\% & 0,077 & 0,077 & 0,077 & 0,077 & 0,077 \\
\hline L-treonina - 98,5\% & 0,031 & 0,081 & 0,129 & 0,179 & 0,230 \\
\hline L-triptofano - $99 \%$ & 0,012 & 0,012 & 0,012 & 0,012 & 0,012 \\
\hline Ácido glutâmico - 99\% & 0,273 & 0,204 & 0,137 & 0,068 & 0,000 \\
\hline Total & 100,00 & 100,00 & 100,00 & 100,00 & 100,00 \\
\hline \multicolumn{6}{|l|}{ Composição calculada } \\
\hline Proteína bruta, $\%{ }^{2}$ & 17,31 & 17,31 & 17,31 & 17,31 & 17,31 \\
\hline Energia digestível, $\mathrm{kcal} / \mathrm{kg}^{3}$ & 3.398 & 3.399 & 3.399 & 3.399 & 3.399 \\
\hline Energia metabolizável, $\mathrm{kcal} / \mathrm{kg}^{3}$ & 3.247 & 3.247 & 3.247 & 3.247 & 3.247 \\
\hline Energia líquida, $\mathrm{kcal} / \mathrm{kg}^{3}$ & 2.465 & 2.465 & 2.465 & 2.465 & 2.466 \\
\hline Lisina digestível, $\%^{4}$ & 0,960 & 0,960 & 0,960 & 0,960 & 0,960 \\
\hline Met + Cis digestível, $\%{ }^{4}$ & 0,550 & 0,550 & 0,550 & 0,550 & 0,550 \\
\hline Treonina digestível, $\%{ }^{4}$ & 0,551 & 0,599 & 0,645 & 0,693 & 0,741 \\
\hline Triptofano digestível, $\%{ }^{4}$ & 0,180 & 0,180 & 0,180 & 0,180 & 0,180 \\
\hline Arginina digestível, $\%{ }^{4}$ & 0,987 & 0,987 & 0,987 & 0,987 & 0,987 \\
\hline Cálcio, $\%^{2}$ & 0,647 & 0,647 & 0,647 & 0,647 & 0,647 \\
\hline Fósforo disponível, $\%^{3}$ & 0,270 & 0,270 & 0,270 & 0,270 & 0,270 \\
\hline
\end{tabular}

${ }^{1}$ Suplemento vitamínico e mineral para suínos em crescimento; aditivo antimicrobiano promotor de crescimento leucomicina $30 \% ;{ }^{2}$ valores analisados; ${ }^{3}$ valores calculados com base na composição analisada e nos valores propostos por Rostagno et al. (2005); ${ }^{4}$ valores calculados com base na composição de aminoácidos analisados e nos valores de digestibilidade dos aminoácidos dos ingredientes propostos por Rostagno et al. (2005).

O fornecimento de ração foi definido tendo como base o peso metabólico $\left(\mathrm{kg}^{0,75}\right)$ de cada suíno e o consumo médio registrado no período de adaptação. Os arraçoamentos foram realizados às 8 e $16 \mathrm{~h}$. Foram fornecidos $50 \%$ do total de ração de manhã e $50 \%$ à tarde, proporção definida tendo como base os consumos entre a manhã e a tarde no período de adaptação. A água foi oferecida no próprio comedouro na proporção de $3 \mathrm{~mL}$ de água/g de ração. 
Foi utilizado o método de coleta total de fezes, utilizando o óxido de ferro como marcador fecal $\left(2 \%\right.$ de $\left.\mathrm{Fe}_{3} \mathrm{O}_{2}\right)$. As fezes foram coletadas uma vez ao dia, acumuladas em sacos plásticos e armazenadas em freezer $\left(-18^{\circ} \mathrm{C}\right)$. A urina dos suínos foi coletada em baldes de plástico, contendo $20 \mathrm{ml}$ de $\mathrm{HCl}$ 1:1 para evitar a proliferação bacteriana e possíveis perdas por volatilização. A determinação da composição química das fezes, urina, alimentos e rações foi realizada segundo as metodologias descritas por Silva e Queiroz (2002).

Os valores de nitrogênio consumido (NC), nitrogênio excretado nas fezes (NF) e excretado na urina (NU) foram obtidos pela multiplicação dos teores de nitrogênio pelas quantidades de ração consumida, de fezes e de urina excretadas, respectivamente. A partir desses valores, foram calculados o $\mathrm{N}$ retido $(\mathrm{NR}=\mathrm{NC}-\mathrm{NF}-\mathrm{NU})$, a utilização líquida de proteína $(U L P=N R / N C)$ e $\mathrm{o}$ valor biológico da proteína dietética $(\mathrm{VBPD}=$ $\mathrm{NR} /(\mathrm{NC}$ - NF)), conforme indicado por Adeola (2001). Foram colhidas amostras de sangue no final do experimento, via veia cava cranial, para a determinação do nitrogênio da ureia plasmática (NUP) (Marsh et al., 1965).

Os resultados obtidos foram submetidos à análise de regressão polinomial de acordo com o seguinte modelo estatístico: $\mathrm{Y}_{i j}=\mu+\mathrm{N}_{i}+\mathrm{e}_{i j}$, em que: $\mathrm{Y}_{i j}=$ valor observado das variáveis estudadas, relativo a cada indivíduo $\mathrm{j}$, recebendo a relação $\mathrm{i} ; \mu=$ constante geral; $\mathrm{N}_{i}=$ relações TL, sendo $\mathrm{i}=0,574 ; 0,624 ; 0,673 ; 0,722$ e 0,$772 ; \mathrm{e}_{i j}=$ erro-aleatório associado a cada observação. Para as variáveis que apresentaram efeito quadrático, as equações obtidas foram derivadas, para obtenção do ponto de máximo ou de mínimo nas relações TL.

No experimento II, foram utilizados 60 suínos, 30 machos castrados e 30 fêmeas, híbridos comerciais, da mesma linhagem dos animais utilizados no experimento I, com peso inicial de $15,5 \pm 1,5 \mathrm{~kg}$, sendo a unidade experimental (UE) constituída de uma baia com dois animais do mesmo sexo. As temperaturas mínima e máxima médias, registradas no período experimental, foram de $16,6 \pm 4,1^{\circ} \mathrm{C}$ e $26,6 \pm 3,6^{\circ} \mathrm{C}$, respectivamente. As umidades relativas do ar médias do período experimental, pela manhã e pela tarde, foram de $83,2 \pm 10,5 \%$ e $55,7 \pm 12,9 \%$, respectivamente.
As rações experimentais foram as mesmas descritas no experimento I (Tab. 1), de modo a avaliar os efeitos das relações TL dessas rações sobre o desempenho de leitões em condição de criação em nível de campo. As rações e a água foram fornecidas à vontade. Os animais foram distribuídos em um delineamento em esquema fatorial 5 × 2 (cinco relações treonina:lisina digestíveis e dois sexos), com três repetições por tratamento (três repetições de machos castrados e três repetições de fêmeas). Os animais foram pesados no início e no final da fase, e avaliaramse o consumo diário de ração (CDR), o ganho diário de peso (GDP) e a conversão alimentar (CA). Foram coletadas amostras de sangue para a determinação do NUP, utilizando-se as mesmas metodologias de coleta e de análises do experimento I.

As variáveis estudadas foram submetidas à análise de variância, de acordo com o modelo estatístico: $\mathrm{Y}_{i j k}=\mu+\mathrm{N}_{i}+\mathrm{G}_{j}+\mathrm{NxG}+\mathrm{e}_{i j k}$, em que: $\mathrm{Y}_{i j k}=$ variáveis estudadas; $\mu=$ constante geral; $\mathrm{N}_{i}=$ relações TL, sendo $\mathrm{i}=0,574 ; 0,624$; 0,$673 ; 0,722$ e 0,$772 ; \mathrm{G}_{j}=$ efeito do sexo j $(1=$ macho, 2 = fêmea); $\mathrm{NxG}=$ interação relação TL e sexo e $\mathrm{e}_{i j k}=$ erro-aleatório associado a cada observação. Os graus de liberdade referentes às relações TL foram desdobrados em polinômios e, para as variáveis que apresentaram efeito quadrático, foram feitas as derivações das equações, para obtenção da melhor relação TL.

\section{RESULTADOS E DISCUSSÃO}

Os resultados do primeiro experimento, balanço de nitrogênio, encontram-se na Tab. 2. Não foram observados efeitos $(\mathrm{P}>0,05)$ da relação $\mathrm{TL}$ sobre a NF, nitrogênio absorvido (NAB), NU, VBPD e NUP.

Houve efeito $(\mathrm{P}<0,05)$ quadrático, com ponto de máximo, da relação TL sobre os valores de NR e ULP, assim como efeito quadrático, com ponto de mínimo, para nitrogênio total excretado (NTE), variável resultante da soma dos valores do nitrogênio excretado na urina e nas fezes, cujo efeito está relacionado ao melhor perfil de aminoácidos das dietas com TL intermediária. Isso permitiu maior retenção e utilização do $\mathrm{N}$, assim como menor excreção ao ambiente. A derivação das equações obtidas para NR, ULP e NTE (Fig. 1) forneceu os valores de 0,648, 0,649 e 0,648 , respectivamente. 
Tabela 2. Nitrogênio consumido (NC), $\mathrm{N}$ fecal (NF), $\mathrm{N}$ absorvido (NAB), $\mathrm{N}$ da urina (NU), $\mathrm{N}$ total excretado (NTE), N retido (NR), utilização líquida de proteína (ULP), valor biológico da proteína dietética (VBPD) e nitrogênio da ureia plasmática (NUP) de suínos na fase inicial de 15 aos $30 \mathrm{~kg}$, de acordo com a relação treonina:lisina (TL) digestíveis

\begin{tabular}{|c|c|c|c|c|c|c|c|c|}
\hline \multirow{2}{*}{ Item } & \multicolumn{5}{|c|}{ Relação treonina:lisina digestíveis } & \multirow{2}{*}{ Média $\pm D P$} & \multirow{2}{*}{$\mathrm{CV}$} & \multirow{2}{*}{ Efeito $^{1}$} \\
\hline & 0,574 & 0,624 & 0,673 & 0,722 & 0,772 & & & \\
\hline $\mathrm{NC}, \mathrm{g} / \mathrm{d}$ & 30,83 & 31,86 & 29,97 & 28,77 & 30,63 & $30,41 \pm 4,03$ & - & - \\
\hline $\mathrm{NF}, \mathrm{g} / \mathrm{d}$ & 5,05 & 4,97 & 4,34 & 3,85 & 5,10 & $4,66 \pm 1,04$ & 17,64 & NS \\
\hline $\mathrm{NAB}, \mathrm{g} / \mathrm{d}$ & 25,77 & 26,88 & 25,62 & 24,92 & 25,53 & $25,75 \pm 3,63$ & 3,61 & NS \\
\hline $\mathrm{NU}, \mathrm{g} / \mathrm{d}$ & 8,11 & 8,09 & 7,54 & 8,44 & 8,71 & $8,18 \pm 1,57$ & 12,60 & NS \\
\hline NTE, $g / d$ & 13,16 & 13,06 & 11,89 & 12,29 & 13,81 & $12,84 \pm 2,07$ & 5,45 & $\mathrm{Q}=0,026$ \\
\hline $\mathrm{NR}, \mathrm{g} / \mathrm{d}$ & 17,66 & 18,79 & 18,08 & 16,48 & 16,83 & $17,57 \pm 2,66$ & 3,98 & $\mathrm{Q}=0,026$ \\
\hline ULP, \% & 57,09 & 59,16 & 60,04 & 57,18 & 55,22 & $57,74 \pm 3,96$ & 3,86 & $\mathrm{Q}=0,031$ \\
\hline VBPDP, \% & 68,44 & 70,14 & 70,20 & 66,02 & 66,31 & $68,22 \pm 3,78$ & 4,87 & NS \\
\hline NUP, mg/dl & 15,17 & 15,86 & 16,28 & 15,01 & 15,53 & $15,63 \pm 1,10$ & 9,21 & NS \\
\hline
\end{tabular}

CV=coeficiente de variação. ${ }^{1}$ Análise de regressão: $\mathrm{Q}=$ efeito quadrático: $\mathrm{NTE}=55,31057$ - 132,76680TL + $102,4093 \mathrm{TL}^{2} ; \mathrm{NR}=24,89953+132,76680 \mathrm{TL}-102,4093 \mathrm{TL}^{2} ; \mathrm{ULP}=-72,89688+407,76581 \mathrm{TL}-314,08100 \mathrm{TL}^{2} ; \mathrm{NS}^{2}=$ não-significativo.

A utilização líquida da proteína (fração do nitrogênio retido em relação ao consumido) obtida apresentou média de $57,7 \%$, sendo maior que os valores de 30 a $40 \%$, geralmente observados na suinocultura (Oliveira, 2001). Contudo, o presente trabalho foi realizado com dietas de baixa proteína bruta $(3 \%$ inferior ao indicado pelo NRC (Nutrient..., 1998), calculadas de acordo com o conceito de proteína ideal, para suínos de média a elevada deposição de tecido magro. Segundo Canh et al. (1998), para cada ponto percentual reduzido no teor de proteína bruta das dietas, pode-se reduzir em até $10 \%$ a excreção de nitrogênio de suínos.

Os valores obtidos para a otimização das variáveis NR, ULP e NTE foram próximos ao indicado pela Ajinomoto (1990), TL de 0,650 para leitões de $9 \mathrm{~kg}$ de peso, assim como ao valor da relação indicada pela Ajinomoto (2003), TL de 0,658 para leitões de $45 \mathrm{~kg}$ de peso. Da mesma forma, os resultados obtidos foram semelhantes aos relatados por Murphy (1998), os quais indicaram a relação TL de 0,642 para suínos dos 20 aos $50 \mathrm{~kg}$ de peso.

Não houve efeito $(\mathrm{P}>0,05)$ do nível de treonina sobre a variável NUP, resultado diferente dos encontrados por Defa et al. (1999), que verificaram, para leitões dos 17 aos $30 \mathrm{~kg}$, redução linear do NUP com o aumento da treonina e dos verificados por Pedersen et al. (2003), que observaram efeito quadrático, com ponto de mínimo para o NUP, com o aumento da relação TL em amostras de sangue coletado duas horas após a alimentação.

Segundo Coma et al. (1995), valores baixos de NUP estão relacionados com a melhor utilização de nitrogênio para a deposição de tecido, diferente dos resultados obtidos neste experimento para a retenção e a excreção do nitrogênio. Pedersen et al. (2003) não encontraram efeitos do aumento das relações TL sobre o NUP, quatro e seis horas após a alimentação, resultado semelhante ao obtido no presente experimento.

A recomendação obtida para este experimento foi a TL de 0,649, resultado da média das derivações da NR e da ULP. Foram tomadas como base essas duas variáveis por terem apresentado os menores coeficientes de variação. O valor recomendado, TL de 0,649 , é próximo aos resultados já citados. Contudo, o valor dessa recomendação é inferior ao indicado por Rodrigues et al. (2001), TL de 0,750. As diferenças entre os experimentos, provavelmente, estão ligadas às diferenças no potencial genético para deposição de carne dos suínos (Moreira, 1998). 


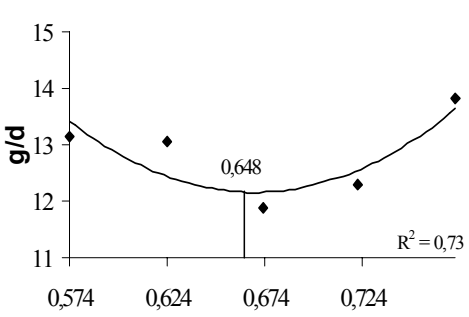

$\mathrm{NTE}=55,31057-132,76680 \mathrm{TL}+102,4093 \mathrm{TL}^{2}$

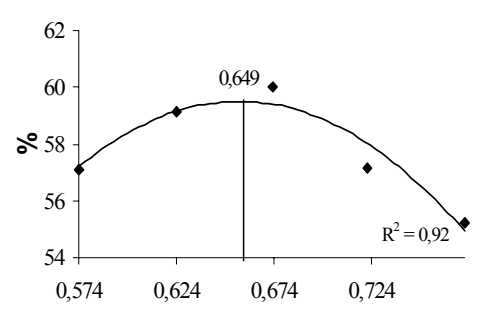

$\mathrm{ULP}=-72,896+407,765 \mathrm{TL}-314,081 \mathrm{TL}^{2}$

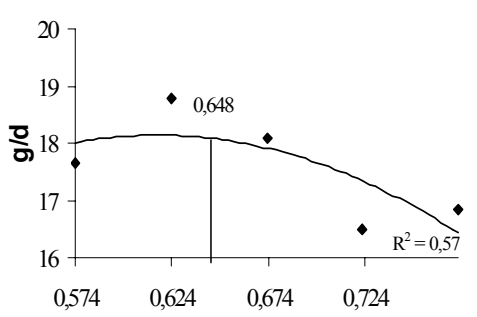

$\mathrm{NR}=24,89953+132,76680 \mathrm{TL}-102,4093 \mathrm{TL}^{2}$

Relação treonina:lisina digestíveis

Figura 1. Nitrogênio total excretado (NTE), utilização líquida de proteína (ULP) e nitrogênio retido (NR) de suínos na fase inicial, de 15 a 30kg de peso, de acordo com a relação treonina:lisina digestíveis.

Os resultados do experimento II estão na Tab. 3 . Não houve interação $(\mathrm{P}>0,05)$ relação $\mathrm{TL}$ versus sexo, indicando que, nesta fase, a resposta no desempenho de machos e fêmeas para as diferentes relações TL é semelhante. Não houve $(\mathrm{P}>0,05)$ diferença no desempenho entre os machos e as fêmeas, sugerindo que não existem diferenças entre sexos nesta fase ou que não foram suficientemente grandes para afetarem o desempenho. Estes resultados são semelhantes aos de Cadogan et al. (1998), que estudaram níveis de treonina para leitões desmamados e em terminação e não observaram diferenças nas exigências para machos castrados, machos inteiros e fêmeas.

Tabela 3. Consumo diário de ração (CDR), ganho diário de peso (GDP), conversão alimentar (CA) e nitrogênio da ureia plasmática (NUP) de suínos na fase inicial, de 15 aos 30kg de peso, de acordo com a relação treonina:lisina (TL) digestíveis

\begin{tabular}{|c|c|c|c|c|c|c|c|c|c|c|c|}
\hline \multirow{3}{*}{ Item } & \multicolumn{9}{|c|}{ Relação treonina:lisina digestíveis } & \multirow{3}{*}{\multicolumn{2}{|c|}{$\mathrm{CV}$}} \\
\hline & \multicolumn{3}{|c|}{ Macho } & & \multicolumn{4}{|c|}{ Fêmea } & \multirow{2}{*}{$\bar{X}$} & & \\
\hline & $0,5740,624$ & 0,673 & $0,7220,772$ & & $0,5740,624$ & 0,673 & 0,722 & 0,772 & & & \\
\hline CDR, kg & $1,2401,234$ & 1,144 & $1,2671,233$ & 1,223 & $1,2961,155$ & 1,242 & 1,239 & 1,249 & 1,236 & 8,51 & NS \\
\hline GDP, $\mathrm{g}$ & $608 \quad 624$ & 599 & 601633 & 613 & $592 \quad 593$ & 637 & 627 & 615 & 613 & 7,88 & NS \\
\hline $\mathrm{CA}$ & $2,0391,976$ & 1,889 & $2,1081,947$ & 1,992 & $2,191 \quad 1,966$ & 1,947 & 1,988 & 2,029 & 2,024 & 5,92 & $\mathrm{Q}=0,06$ \\
\hline NUP, mg/dl & $15,6614,14$ & 15,35 & $16,7216,09$ & 15,59 & $14,0213,79$ & 14,55 & 15,31 & 14,13 & 14,33 & 11,60 & NS \\
\hline
\end{tabular}

$\mathrm{CV}=$ coeficiente de variação; ${ }^{\mathrm{NS}}=$ não significativo; $\mathrm{Q}=$ efeito quadrático da relação TL; $\mathrm{CA}=6,81622-14,07749 \mathrm{TL}+$ $10,19189 \mathrm{TL}^{2} ; \mathrm{P}=0,06$.

Não houve $(\mathrm{P}>0,05)$ efeito da relação TL sobre o consumo diário de ração (CDR) dos leitões. Estes resultados são semelhantes aos de Berto et al. (2002), que, ao estudarem níveis crescentes de adição de treonina para leitões dos 16 aos $23 \mathrm{~kg}$, não encontraram efeitos sobre o CDR. Contudo, é diferente dos resultados obtidos por Defa et al. (1999), que encontraram redução linear no consumo com a inclusão de níveis crescentes de treonina para leitões dos 17 aos $29 \mathrm{~kg}$ de peso.
Segundo De Blas et al. (2000), níveis elevados de treonina resultaram em maior concentração sanguínea de treonina após as refeições, dificultando a sua metabolização, o que pode resultar em redução da ingestão de alimentos por afetar os centros hipotalâmicos da saciedade.

Os resultados também diferiram dos obtidos por Pozza et al. (2000), os quais, em experimento com níveis de suplementação de treonina para 
leitoas dos 15 aos $30 \mathrm{~kg}$ de peso, observaram efeito quadrático com ponto de mínimo para o CDR. As diferenças entre os resultados dos experimentos podem estar relacionadas ao material genético com o qual os autores trabalharam ou ao nível de proteína da dieta, temperatura e ou ingredientes utilizados nos experimentos.

Não houve $(\mathrm{P}>0,05)$ efeito das relações TL sobre o GDP dos leitões. Estes resultados foram semelhantes aos reportados por Defa et al. (1999), Pozza et al. (2000) e Berto et al. (2002), mas diferiram dos resultados de Ajinomoto (1990, 2003), que verificou aumento no GDP com o aumento da relação TL. Da mesma forma que para as demais variáveis, as diferenças no potencial genético dos animais estudados podem estar levando a essas diferenças de resultados (Moreira, 1998; Rodrigues et al., 2001).

Para a variável CA, diferentemente das demais variáveis de desempenho, houve efeito quadrático $(\mathrm{P}=0,06)$, com ponto de mínimo na relação TL de 0,691. Resultados semelhantes para a conversão alimentar foram descritos por Pozza et al. (2000) e Berto et al. (2002), em estudos com variação na relação treonina:lisina, e por Arouca et al. (2004, 2005), ao estudarem níveis de lisina na dieta de animais em terminação, com base no conceito de proteína ideal. Essa melhora dos resultados da conversão alimentar reforça os obtidos no balanço de nitrogênio (Tab. 2), ou seja, a melhora no perfil de aminoácidos pode ter favorecido a deposição de tecido pelos leitões. Essa relação foi mais alta que a relação no experimento $\mathrm{I}, 0,649$, e a indicada pelo NRC (Nutrient..., 1998), 0,625, para leitões com o mesmo potencial genético dos utilizados neste experimento. No entanto, foi próxima à sugerida pela Ajinomoto (2000), 0,680 , para minimizar a conversão alimentar de suínos dos 45 aos $90 \mathrm{~kg}$ de peso, e das recomendações de Cadogan et al. (1998), 0,670, e de Murphy (1998), 0,700.

A diferença entre os resultados dos experimentos I e II, embora estes tenham sido realizados com animais de características genéticas semelhantes, provavelmente está relacionada às condições experimentais. Os animais do experimento I foram mantidos em ambiente controlado, sala de metabolismo, com baixos desafios sanitários, social e ambiental, enquanto os do experimento
II foram mantidos em ambiente comum de criação de suínos, para a respectiva fase, estando mais susceptíveis às adversidades da criação.

Segundo Defa et al. (1999), para máxima resposta imune, os leitões devem receber níveis de treonina acima dos recomendados para o máximo desempenho. Os resultados obtidos deste estudo confirmam que os animais criados em condições de campo (experimento II) necessitaram de maior relação TL, 0,691. Embora a relação obtida tenha sido mais alta que a de alguns experimentos citados, foi menor que a indicada por Rodrigues et al. (2001), 0,750, para leitões dos 30 aos $60 \mathrm{~kg}$ de peso, com elevada deposição de carne magra. Essas diferenças, já discutidas por outros autores (Pozza et al., 2000; De Blas et al., 2006), estão, provavelmente, relacionadas ao estágio físiológico dos animais e aos fatores já mencionados nessa discussão.

\section{CONCLUSÕES}

A melhor relação treonina:lisina digestíveis, em rações de leitões dos 15 aos $30 \mathrm{~kg}$ de peso, para maximizar a retenção de nitrogênio, é 0,649 e, para a melhor conversão alimentar, é de 0,691.

\section{REFERÊNCIAS BIBLIOGRÁFICAS}

ADEOLA, O. Digestion and balance techniques in pigs. In: LEWIS, A.J.; SOURTHERN, L.L. Swine nutrition. 2.ed. Boca Raton: CRC, 2001. p.903-916.

AJINOMOTO. A suplementação de L-treonina melhora significativamente o desempenho de leitões alimentados com dietas de baixas proteinas. São Paulo: Ajinomoto Biolatina, 1990. (Relatório de pesquisa, 5). Disponível em: $<$ http://www.lisina.com.br/>. Acessado em: 24 jun. 2006.

AJINOMOTO. Exigências de treonina para suínos: benefícios da suplementação de L-Treonina. São Paulo: Ajinomoto Biolatina, 2003. (Informativo técnico, 10). Disponível em: $<$ http://www.lisina.com.br/>. Acessado em: 24 jun. 2006.

AJINOMOTO. Relação treonina:lisina para ótimo desempenho de suínos em final da terminação. São Paulo: Ajinomoto Biolatina, 2000. (Relatório de pesquisa, 30). Disponível em: $<$ http://www.lisina.com.br $>$. Acessado em: 24 jun. 2006. 
AROUCA, C.L.C.; FONTES, D.O.; FERREIRA, W.M. et al. Exigências de lisina, com base no conceito de proteína ideal, para suínos machos castrados, de 95 a $122 \mathrm{~kg}$, selecionados para deposição de carne magra. Arq. Bras. Med. Vet. Zootec., v.56, p.773-781, 2004

AROUCA, C.L.C.; FONTES, D.O.; VELOSO, J.A.F. et al. Exigências de lisina, com base no conceito de proteína ideal, para suínos machos castrados dos 96 aos $120 \mathrm{~kg}$, selecionados para eficiência de crescimento. Arq. Bras. Med. Vet. Zootec., v.57, p.104-111, 2005.

BERTO, D.A.; WECHSLER, F.S.; NORONHA, C.C. Exigências de treonina de leitões dos 7 aos 12 e dos 12 aos 23kg. Rev. Bras. Zootec., v.31, p.11761183, 2002.

CADOGAN, D.J.; CHUNG, T.K.; CAMPBELL, R.G. et al. Effects of dietary threonine on the growth performance of entire male, female, and castrated male pigs between 6 and $14 \mathrm{~kg}$ live weight. In: MEETING OF THE AMERICAN SOCIETY OF ANIMAL SCIENCE. MIDWESTERN SECTION, 1998, Des Moines, IA. Proceedings... Savoy, IL: ASAS, 1998. Abstr. 49.

CANH, T.T.; AARNINK, A.J.A.; SCHUTTE, J.B. et al. Dietary protein affects nitrogen excretion and ammonia emission from slurry of growing-finishing pigs. Livest. Prod. Sci., v.56, p.181-191, 1998.

COMA, J.; CARRION, D.; ZIMMERMAN, D.R. Use of plasma urea nitrogen as a rapid response criterion to determine the lysine requirement of pigs. J. Anim. Sci., v.73, p.472-481, 1995.

DE BLAS, C.; GARCÍA, A.I.; CARABAÑO, Y.R. Necesidades de treonina en animales monogástricos necesidades de treonina en animales monogástricos. In: CURSO DE ESPECIALIZACIÓN FEDNA: AVANCES EN NUTRICION Y ALIMENTACIÓN ANIMAL, 16., 2000, Barcelona. Madrid: Fedna, 2000. Disponível em: $<$ http://www.etsia.upm.es/fedna/

capitulos/00CAP1.pdf/>. Acessado em: 25 ago. 2006.

DEFA, L.; CHANGTING, X.; SHIYAN, Q. et al. Effects of dietary threonine on performance, plasma parameters and immune function of growing pigs. Anim. Feed Sci. Technol., v.78, p.179-188, 1999.

MARSH, W.H.; FINGERHUT, B.; MILLER, H. Automated and manual direct methods for determination of the determination of blood urea. Clin. Chem., v.11, p.624-627, 1965.
MOREIRA, I. Nutrição de rebanhos de suínos geneticamente melhorados. In. SIMPÓSIO NACIONAL DE MELHORAMENTO ANIMAL, 2., 1998, Uberaba. Anais... Uberaba: SBMA, 1998. v.1, p.177-183.

MURPHY, J. Advances in swine nutrition to address nutrient management issues. Guelph: Ontário Ministry of Agriculture, Food, and Rural Affairs, 1998. Disponível em: $<$ http://www.omafra.gov.on.ca/english/livestock/sw ine/facts/ nmannutr.htm>. Acessado em: 24 jun. 2006.

NUTRIENT requirements of swine. 10.ed. Washington: NRC, 1998. 189p.

OLIVEIRA, P.A.V. Produção e manejo de dejetos suínos. In: SOARES, W.R. A produção animal na visão dos brasileiros. Piracicaba: FEALQ, 2001. p.164-177.

PEDERSEN, G.; LINDBERG, J.E.; BOISEN, S. Determination of the optimal dietary threonine:lysine ratio for finishing pigs using three different methods. Livest. Prod. Sci., v.82, p.233243, 2003.

PEKAS, J.C. Versatible swine laboratory apparatus for physiologic and metabolic studies. J. Anim. Sci., v.27, p.1303-1306, 1968.

POZZA, P.C.; GOMES P.C.; DONZELE, J. L. et al. Exigência de treonina para leitoas dos 15 aos 30kg. Rev. Bras. Zootec., v.29, p.817-822, 2000.

RODRIGUES, N.E.B.; DONZELE, J.L.; OLIVEIRA, R.F.M. et al. Níveis de treonina em rações para leitoas com alto potencial genético para a deposição de carne magra dos 30 aos $60 \mathrm{~kg}$. Rev. Bras. Zootec., v.30, p.2039-2045, 2001.

ROSTAGNO, H.S.; ALBINO, L.F.T.; DONZELE, J.L. et al. Tabelas brasileiras para aves e suinos: composição de alimentos e exigências nutricionais. 2.ed. Viçosa: UFV, 2005. 186p.

SILVA, D.J.; QUEIROZ, A.C. Análise de alimentos: métodos químicos e biológicos. 3.ed. Viçosa: UFV, 2002. 235p.

THONG, H.T.; LIEBERT, F. Amino acid requirement of growing pigs depending on amino acid efficiency and level of protein deposition. $2^{\text {nd }}$ communication: threonine. Arch. Anim. Nutr., v.58, p.157-168, Apr. 2004. 